\title{
The Perceptions of Faith-based Healing among Public Health Practitioners and Pentecostal-Charismatic Believers in the Eastern Cape Province
}

\author{
Nelly Sharpley \\ ORCID iD: https://orcid.org/0000-0001-7657-4033
}

\section{Chammah J. Kaunda \\ ORCID iD: https://orcid.org/0000-0001-6879-6330}

\begin{abstract}
This paper analyses the perceptions of public health practitioners and a Pentecostal-Charismatic community of faith-based healing in Eastern Cape. Data was collected through qualitative techniques, which included observations, questionnaires and in-depth interviews. The qualitative data was analyzed using an interpretive approach. The findings demonstrate a conflict between public health practitioners and Pentecostal-Charismatic believers on the issue of faith-based healing. While the public health practitioners argue for the medical model, which is a reductionist approach to health problems, Pentecostal-Charismatic believers argue for a purely religious model, which is another reductionist approach to health challenges in Eastern Cape. This article argues, as a way of bridging the knowledge gap, for a more systematic transformation of public health by acknowledging the role of faith in people's lives and consequently reconceptualizes relationships between faith and health problems in the province.
\end{abstract}

Keywords: Health Practitioners; health and healing; Pentecostal-Charismatic Believers; Holistic Approach; Perceptions; Eastern Cape. 


\section{Introduction}

The current studies on public health increasingly acknowledge that health and healing are not merely physiological pathology or medical issues, but rather issues that intersect with political, social, economic, cultural, and spiritual dimensions (Csordas \& Kleinman 1990; Montgomery et al. 2005; Kaunda \& Phiri 2016). The World Council of Churches (WCC 1990:2) affirms that 'Health is most often an issue of justice, peace, [the] integrity of creation, and spirituality'. Scholars are exploring health and healing within the context of wholeness, concerning aspects of the scientific and non-religious, unscientific and religious, technological and non-technological, and Western and non-Western (Csordas \& Kleinman 1990). Healing is currently defined as 'the process of bringing together aspects of one's self, body-mind-spirit, at deeper levels of inner knowing, leading toward integration and balance with each aspect having equal importance and value' (Montgomery et al. 2005:4). Similarly, health is conceived of as 'the state or process in which the individual [community] experiences a sense of well-being, harmony, unity where subjective experiences about health, health beliefs, and values are honoured' (Montgomery et al. 2005:4).

This article employs holistic healthcare theory to explore the views and perceptions of public healthcare practitioners, as well as that of PentecostalCharismatic believers on faith-based healing in the Eastern Cape. PentecostalCharismatic faith is classified as the kind of faith that embraces the religious philosophy of spiritual gifts and healing (speaking in tongues, passionate worship and laying on of hands), and is independent and non-denominational (Sharpley 2013). The term Charismatic embraces Pentecostalism, and its belief in what is perceived as the leadership of the Holy Spirit (Sharpley 2013). The definitions seem to overlap, and to the general public, the division or difference is blurred. Drawing attention to public health practitioners and PentecostalCharismatic's believers' perceptions of faith-based healing is significant, where previous studies have not adequately demonstrated whether or not there is a possibility of collaboration on public health process between religious communities and public health institutions (Sharpley 2013). Besides this, little is known about whether or not faith-based healing has any significance in public health in South Africa.

The aim addressed here is to find a working solution through a holistic theoretical framework of health and wellness that can best support collabo- 
ration of the medical and religious models of public health in the Eastern Cape. The holistic approach utilised in this article seeks to overcome the separation between the religious or spiritual and scientific understandings of health problems (Kolcaba 2003).

Here, spiritual and physical spheres of human life are blended combining the physical, mental, emotional and spiritual. The application of this blending to faith-based healing, as perceived by the Pentecostal-Charismatics in the Eastern Cape, shows that the holistic framework embraces their sphere of wellness and healthcare in the psycho-spiritual approach. The holistic approach, therefore, encompasses a multidisciplinary approach to public health. It seeks to understand the human person as a unity where body, mind, spirit and environment are descriptors of the interrelated manifestations of the person. Such a framework does not ignore the social, political, behavioural, environmental and spiritual realities of a person, but emphasises the biomedical approach to health and healthcare (Kaunda \& Phiri 2016). The question is: what are the perceptions of Pentecostal-Charismatic believers and health practitioners on faith-based health and healing practices? And how can a holistic framework of healthcare practice promote collaboration in public healthcare processes between Pentecostal-Charismatics and public health practitioners in the Eastern Cape?

\section{Background and Literature Review}

The new public health ideology in South Africa presents health as a crossroads, where biological and social factors, the individual and the community, and social and economic policy all meet (Gilbert et al. 1996). Scholars argue that societies differ in their understanding of health and ways of seeking and organising explanations. They underscore that such differences are shaped by social and cultural factors as well as historical developments (Gilbert et al. 1996; Taylor \& Field 1993; Pretorious et al. 2013). In the public health and epidemiology studies, religion is increasingly suggested as not only one of the key social determinants of health but also a frame people utilise to explain health and healing (Idler, Blevins, Kiser \& Hogue 2017: 1-2). Religion functions as a powerful instrument that informs and shapes most people's notions of health and healing.

Holman (2015) writes that religion is a little of both, with pros and cons when it comes to health and the right to health, and the connection between is 
seen in the social determinants of health. As the World Health Organisation (2008:2) states:

Avoidable health inequalities, arise because of the circumstances in which people grow, live, work, and age; and the systems put in place to deal with illness. The conditions in which people live and die are in turn shaped by political, social, and economic forces. Social and economic policies have a determining impact on whether a child can grow and develop to its full potential and live a flourishing life, or whether its life will be blighted.

Germane to this is the way in which an individual is socialised to understand how his or her health, wellness and illness influences health behaviours and beliefs.

Scholars stress that most external determinants of health lifestyle decisions (i.e. diet, exercise, and alcohol consumption), when and how a person will access health care, as well as internal mediators, such as the response to illness and illness behaviour patterns, are mostly informed by cultural factors; this includes religion for most religious people (Gross 2015). Short and Vissandjée (2017) conducted a study where religion was listed by participants as one of the key determinants of their health. Scholars caution that although religion can be of great benefit to increase social capital and specific healthy behaviour, certain religious beliefs can also preclude much-needed health benefits and interventions (Idler 2014).

The proliferation of Pentecostal-Charismatic churches in South Africa is evidenced by their influence on individuals and their health (Anofuechi 2015). Most people are attracted to Pentecostal-Charismatic churches because these churches provide spiritual, social, and physical support to their members, where health is one of the noted benefits (Lehohla 2004; Anofuechi 2015; Schoeman 2017). Thus, it is essential to understand how both PentecostalCharismatic believers and Public Health Practitioners perceive faith-based healing practices. The primary data was collected through a qualitative method, and thematic interpretive approach was used to explore these perceptions.

\section{Methodological Approach}

The research presented in this article comes from a more extensive study on 
Black Charismatic Churches (BCCMs) in the Eastern Cape, which are affiliated to the Pentecostal-Charismatic faith. The study explored the role of BCCMs on issues of welfare, community development and empowerment. It examined how BCCMs interact with communities in their jurisdiction, local government, civil society, and other faith-based organisations in the Eastern Cape on issues of community development and welfare.

In so doing, local government directorates on service delivery were interviewed, and the questionnaire data from congregants and community members was blended with in-depth interviews. A number of service delivery directorates were interviewed for the initial study, however, for this article, the public health practitioners in the directorate and believers in the BCCM are the focus. This directorate involves liaising with ward councillors on public health, health programmes, in-service training, patients' rights, servicing 26 fixed and four mobile clinics. Public health support services focus on the following: pharmacy services, district health care, health promotion and awareness campaigns. Environmental health is responsible for public health and safety, preventative health, water quality monitoring, food control for formal and informal business, chemical safety, disposal of the dead, pollution control, and pest control.

The total sample for the survey included 100 respondents, of which 50 were church members, and another 50 were community members who were not members of the congregation in the study. A simple random sample was done for the respondents from uMdantsane Township in Buffalo City Metro and as well for church members, and a semi-structured questionnaire was used for the community members and the church members. The in-depth interviews were done using a purposeful sampling of seven church pastors and five church elders. The same technique was utilised with local government directorate for public health. There were two respondents from the public health nursing section, which involves the following: liaising with ward councillors on public health, health programmes, in-service training, patients' rights, servicing 26 fixed, and four mobile clinics. There was one respondent for public health support services, which focuses on: pharmacy services, district health care, health promotion, and awareness campaigns. Data was then analysed through an open coding system and a blended narrative technique. The data presented is both a qualitative and quantitative study of Public Health Practitioners and Pentecostal-Charismatic believers' perceptions of faith-based healing in the Eastern Cape. 


\section{Findings}

The findings suggest that perceptions of health and healing are not only subject to a particular social setting but particular religious beliefs, and for some health practitioners to Western influence. The influence of society and external forces in defining health and illness on an individual was evident in the interviews. Even though other factors are at work, the most interesting one was the belief system based on the Pentecostal-Charismatic faith. Both health practitioners and Pentecostal-Charismatic congregants agreed that the PentecostalCharismatic faith has a lot of influence on most Christians' understanding of health and healing. The belief system of these congregations is a determinant of how their followers view and respond to illness and how they expected and encouraged help-seeking behaviour for better health management and prevention. The findings are divided into two key subthemes, as follows.

\section{Pentecostal-Charismatic Believers' Perceptions}

The Pentecostal-Charismatic respondents believed that 'these congregations are powerful churches'. They argued, 'all social evils like crime, teenage pregnancy, poverty, sickness, HIV and AIDS and such, emanate from spiritual causes, hence through prayer, these get addressed, and through spiritual practices, these get eliminated'. Some respondents stressed that all social problems, including sickness as mental issues with an 'evil spirit' as the source, and in case of sickness, being sick is a physical manifestation of such evil. They believe that the teaching of the power of the word of God transforms people from such mentality. The teachings and interpretations of such scriptures by their pastors is what they adhere to, as they believe it is given to them by God. It is not uncommon to hear congregants repeating the teachings of the pastor for themselves as statements of faith and as a way of life. One pastor explained:

What do we do when sickness attacks us, or lack? We resist the devil by faith so we can benefit from the promises of God, for the just shall walk by faith not by sight. But some of you run to the doctors when sick and take doctor's prescription but not the word, that is doubt, not faith, and without faith, we cannot please God. You want to please God, have faith in His word, His promises. 
Another pastor argued:

That if you go to the doctor, the doctor will tell you what the medical books say, if you go to the psychologists, they will tell you what psychology says; but if you come here at church, I will tell you about the word of God that will stir up your faith to please God so you can get your answers. But, if you replace faith in God's word with such human-derived knowledge, then you will die.

During the interview, it was common to hear some congregants saying, 'I have a pain here, or I think I am coming down with something, but I trust God for we walk not by sight, utshilo uApostle [the Apostle has said so]'. Sometimes they would say:

Ndiva... [I am feeling] something but I will not say it, ndivuyise usatana [to make Satan rejoice], the man of God said last Sunday, by the stripes of Jesus we are healed and if we confess that, it will then come to pass. Hayi [no] I will keep confessing.

These findings confirm Barker's (2007:415) argument that:

The prosperity gospel interprets health and material prosperity as evidence of faith - that is, health and wealth are viewed as gifts of the Spirit and as central to charismatic worship. Based on the interpretation of certain passages of the Bible, the Word of Faith movement holds that health and material prosperity are the rightful rewards for the Christian faithful, but that these need to be claimed. Through faith and the naming of what is rightfully theirs, Pentecostals undertake a confession that becomes energizing [sic] and effective, resulting in receiving [what they have claimed] from God. When people do not receive what they have confessed, it is usually due to a negative confession, unbelief, or a failure to observe the divine laws.

The church members in this study perceive their pastors as 'custodians' of God's mandate of healing. Most of them do not question their pastors' instructions, but they do what they are told to do. The sentiment expressed in 
the following statement was common amongst church members from such congregations: 'Whatever our leaders in church tell us, we will obey it, because we know that they hear from God for us'. For instance, in one of the congregations in Buffalo City Metro, congregants led by the elders of the church, lifted their pastor on a chair and carried him on the shoulders of the four strongest men at the service. They celebrated him and stated: 'God has raised him even above the angels' and 'he has the power to instruct the spirits even the angels what to do'. People with various existential needs ran to receive their miracles as the man of God was given the power to address all such spiritual evils like illness.

Congregants believe their pastors had been given the power by God to overcome evil spirits, and the illnesses they are believed to cause. It is usual for pastors to call for those who need healing and deliverance from evil spirits to come forward for the laying of hands on them, so that they can receive healing and good health. Various respondents noted that if their pastors told them to 'condomise', they would do so as they believe this to be the will of God. One believer said, 'I tell you, we will all gladly do it [use condoms], because it is acceptable and right in the eyes of God, but if they say it's wrong, no matter what the government says we will not do it, because we are not subjects to government but to God's law when government conflict with that law'. This statement shows that not only does their faith shape their response to health issues, but also that their pastors determine their congregants' response to government health promotion messages. Other scholars confirm the view that strong religious beliefs can preclude certain much-needed health benefits and interventions (Idler 2014).

According to the congregants in the study, the pastors present the spiritual aspects their followers observe, for example, the desire to know God; the belief that their leaders are custodians of God's purpose and plan for mankind' and 'viewed as powerful churches with miracles such as healing of the sick people'. Some respondents added, 'Sick people get there and come out healed, so most people go there with the hope of getting healed too'. Their spiritual aspect is seen as the reason for the growth of these ministries in these communities, where people who place their faith in religious-based healing practices are likely to be attracted by these BCCMs. There is a belief amongst most congregants that God has given Pentecostal-Charismatics a mandate to improve the standard of living for all and that they are empowered with 'supernatural' power to overcome social ills, and bring prosperity. 


\section{Public Health Practitioners' Perceptions}

Most health practitioners express the concern that faith-healing churches interfere with Government's efforts to reduce the spread of HIV and AIDS, as they undermine the message put out by health promotion workers. They also claimed that these churches discourage people with chronic illnesses from taking their medication and following doctors' prescriptions. Some local government officials from the Department of Health in the health promotion directorate, expressed some misgivings about faith-healing churches. A female respondent lamented that,

These churches interfere with government activities in areas of health and health promotion, by discouraging people from taking medication when they are sick, as they [the churches] claim that they have healed them through [the] laying on of hands and that if they continue to take medication it is a sign of being faithless and they will not be cured by God's power.

The respondent gave examples of people with HIV and AIDS, TB, diabetics, people suffering from high blood pressure and asthma, noting that, 'Such people depend on continued treatment and these churches undermine government efforts in bringing awareness to people of how to manage such illnesses to reduce the prevalence of deaths related to such'. This issue was raised as a concern by public health practitioners, community, and some church members, as those not affiliated with the congregations in question. Pentecostal-Charismatics were seen to be providing services of exclusively spiritual value, and were not understood to be linked to social services other than burial rights, marriages and emotional support. The local government officials emphasised that whereas government cannot be seen to be promoting the faith-healing interests of any particular religious group, it is more responsive to a collective voice. In their eyes, the government has one mandate to bring quality and affordable health service to all.

A senior Government official on health promotion in Buffalo City Metro stated that she needed to understand the operations of these Charismatic congregations, referring to those in the study, and others in the same municipality as well. She attends all of the congregations around the city of East London as if she were a member, and is taken as such in instances where she stays longer. She wanted 'to understand what makes their members so 
brainwashed to the point of risking their lives, to understand how they indoctrinate their members on things like health and prosperity'. She observed that,

Church members are like students in a class, if, as a teacher, you see that some are not getting what you are saying or do not have the desired results, you should as a genuine leader look closely to them as to see what is it that they are missing. This has to work equally for all, do not just be happy in taking their money and counting your income without seeing if what you teach is working for them.

She discovered some pastors were taking people with chronic diseases off their medication. She underscored that 'It is wrong to take people out of [sic] medication when you have not tested the results of your prayer, because what we see now is more people dying of something that can be managed medically'. The official noted the importance of educating the pastors about medical health to enrich their faith-healing practices. Her opinion was representative of other officials where she noted that only certified medical professionals should preside over the suspension of chronic medications, and that pastors should not interfere.

A community member from Nelson Mandela Metropol Municipality in Port Elizabeth argued that 'these churches have a tendency of selling what they term to be God's help to people by saying 'if you give, God will help you or heal you', that is, asking for money before they help or pray for you'. These statements speak to the question of how health professionals and the general public view the way in which these churches deal with illness. At the same time, the public acknowledges the critical welfare support these congregations give to people affected and infected with sicknesses like HIV and AIDS, even though they question the claims of their faith. However, public health practitioners have not yet acknowledged that they also require some religious and spiritual training to understand the spiritual needs of their patients.

The findings present a variety of interaction between health practitioners and Pentecostal-Charismatics on faith-based healing, and a need to find common ground in as far as illness management in the province. The discussion below presents a scholarly analysis of a proposed approach to illness management through health behaviour emanating from a holistic approach to medicine. 


\section{Discussion}

The question of faith-based healing was not just an issue pointed to by congregants, but they also drew attention to the way their faith socialises them and causes them to have a certain perception about themselves, their lives, their health, and their interaction with other people. Firstly, they view their churches as more powerful than all social evils including sickness, and their pastors as custodians of God's will for them. This shows that faith provides them a global point of reference, and the authority of their pastors as representatives of God's will for them. To obey their pastors is to obey God, and this they say with passionate conviction. This obedience shows that their understanding of health and illness lie at the intersection of different social and cultural perspectives that determine a given individual's response to their health concerns (Patterson 1998). It also suggests that health and illness management in the Eastern Cape and thus in South Africa, are not only in the domain of medically trained public health practitioners but also influenced by multiple social and cultural beliefs and practices. Health is not just a matter of medicine, but also a significant matter of people's understanding and interpretation of their spiritual reality. The Pentecostal-Charismatic congregants reveal that their faith influences their notion of health and healing. Thus, to them, health promotion is a strong spiral of spiritual, social, mental realities and values that display who they are and who they want to be (Pretorious et al. 2013: 109-111). This integrated view of health is based on the African holistic approach of reality, where health is not an objective affair in which medical science and research rules; but the people's belief systems also influence their health and wellness. On the other hand, the government's mandate of public health in South Africa is to have a healthy society through effective disease management and prevention based on medical science and research. The primary factor amongst PentecostalCharismatic members is their faith in God.

The members of Pentecostal-Charismatics view faith as pleasing to God, and good health as a consequence of their faith in God. As a respondent argued, 'I would rather die believing God for at least I know where I am going than lose my faith and end in hell'.

Since public health concerns the health of the public, it is more important for public health practices to be sensitive to their patients' religious practices, and to supply a sense of comfort, rather than conflict to their patients. It also implies the current need for an understanding of religion in medical practice through discussion with patients and the general public, especially the 
Pentecostal-Charismatics. Secular organisations such as the World Health Organisation (WHO) are increasingly embracing spirituality as one of the social determinants of health (WHO 2008). The WHO has gone so far as to actively propose that physicians ascertain the religious orientations of their patients, allowing religion and health to be fused, as is the case within African traditional societies. Rather than arguing that Pentecostal-Charismatics' spiritualisation of health and healing obscures systemic causes of oppression and injustice when seeking to assist their members in decision-making concerning their health and illness behaviours, there is a need to create a space for faith-based healing practices for patients who believe in such healing. In contexts such as Swaziland, the church works hand-in-hand with the health department, as well as chiefs and community members, especially in dealing with HIV and AIDS. The church does not per se ignore the relevance of modern medicine while bringing spiritual support and care to people. There is a mutual understanding between modern medicine and faith in assisting people affected by the pandemic. There seems to be an agreement of what each party can do or has to do to assist. For example, Wyngaard (2013:226) observes the following:

Researchers seem to agree that spirituality is an important component of the holistic care approach commonly found in palliative care. Shiselweni Home-Based Care (SHBC) is a Faith Based Organisation in Swaziland working amongst people with HIV and AIDS in the poorest and most affected areas of the country. They endeavour to restore and build up each clients' dignity through the way in which they are approached, not only when giving physical assistance, but also when they address their spiritual needs. This article emphasises the need for spiritual care as part of the caregiving program and then also illustrates the positive feelings of both the SHBC caregivers as well as their clients as they share some of the experiences encountered during spiritual care.

Similarly, Denis (2013:58) argues as follows:

As the HIV/AIDS epidemic enters its fourth decade, there is a growing recognition that HIV/AIDS is far more than a biomedical phenomenon. It affects politics, culture, social relations, material life 
and also, of course, religion. This paper shows that the study of HIV/AIDS and religion, after a slow start, has shown a considerable development, not least in sub-Saharan Africa. The CHART Online Bibliographic Database, incomplete as it is, is a testimony to the importance of this new field of research. The good news is that social scientists and theologians, after ignoring each other, show signs of being prepared to learn from each other. HIV/AIDS and religion exercise on each other a mutual influence. We understand better the role of religious beliefs and practices in shaping the lives of people affected or infected by HIV. But this is not a one-way movement. The epidemic also changes the institutional structures, the beliefs, the moral codes and the forms of sociability of religious people. Even if HIV/AIDS enters a new phase, with fewer infections and more people having access to treatment, these new forms of religious life are likely to remain for a long time.

A report by Shabalala and Dlamini (2018:1-3) confirms that the Eastern Cape can learn from these selected cases mentioned above, where a holistic approach to health means coming together to offer a multidisciplinary approach that recognises a person holistically. To bridge a gap that even the medical training institutions in South Africa have acknowledged, an interdisciplinary approach to medicine would address a person in spiritual, social, mental, as well as physical terms. Indeed, the literature underscores that illness in contemporary society finds its expression in social, psychological, spiritual, and environmental ways.

Furthermore, the social context of an individual influences how a person understands and responds to symptoms. Such a social environment includes one's belief system, which cannot be ignored.

The holistic approach appreciates and recognises the significance of religion and spirituality in understanding public health and promoting effective approaches to health management and ill-health prevention. Such an approach is also crucial, as the integration of faith-based practices in public health has the potential to mitigate the problem of health that is compromised as a result of certain religious beliefs and practices. It may also promote a theology of illness behaviour and help-seeking, which integrates medical healthcare interventions and communications with religious practices in terms of embodied experiential of the divine upon 
which most sacred beliefs and practices on which the PentecostalCharismatic faith, amongst others, are based.

\section{Conclusion}

The study presented faith healing as the determining factor on illness management with the Pentecostal-Charismatic followers in the Eastern Cape, SA and the basis and success of this faith healing being congregants' adherence to Pentecostal-Charismatic faith. The Pentecostal-Charismatic congregation in BCCM is a strong determinant to adherence and non-adherence to health promotion messages given by the department of health. The strong confidence that congregants place on their leaders as the voice of God in their lives calls for an allegiance to the kind of faith they promote, insofar as healing is concerned. Collaboration in order to better realise the promotion of health and prevention could be the best approach between religion and government, seeing that people's strong allegiance to their Christian leaders and also their strong faith commitment influences how they deal with their health challenges. The study then calls for an approach of unified efforts between religious-based health and department of health through a holistic approach of faith and health in the Eastern Cape. Such an approach will present a better understanding of the realities of faith in illness, as well as the scientific explanations of the diseases. It will address the gap mentioned before, that is, of a lack of knowledge of the disease as one of the factors influencing the kind of healthseeking behaviour people project.

This understanding indicates better management of the illness to those in need, when empowered with relevant knowledge on chronic illnesses and how to best manage them through medical science and through the navigation of people's belief systems to align such with medicine basically. Also, the call for collaboration can help to bring a platform of awareness to the congregants when their leaders are equipped with a better understanding of illnesses like diabetes, by including the health promotion efforts of health. Faith expressed by the congregants speaks to the healing one receives in believing in the promises of God as true, whereas through its health promotion efforts, Government speaks to wellness through prevention and management by adhering to specific health rules in order to manage an existing illness. Clarity of engagement on these points of influence to an individual will determine one's empowerment to make informed decisions about their health. Also, an 
understanding of the discourses of faith and health in our society would present a platform of engagement that incorporates both structures of faith and health in a community. The holistic approach in the scientific study of health-seeking behaviour of Pentecostal-Charismatic belief-adhering people and the recommenddations presented here will help to bring a multidisciplinary approach to addressing their health-seeking behaviour. It has the potential to facilitate an inclusive social platform with a rich understanding of how to encourage a holistic approach with a multidisciplinary practice.

\section{References}

Anofuechi, B.O. 2015. Pentecostalism and the Further Fragmentation of Christianity: An Investigation of the Factors Contributing to the Establishment of New Churches in Belhar since 2000. Cape Town: University of the Western Cape.

Buso, D.L., B. Longo-Mbenza, P. Bovet, B. van den Borne, A.N. Okwe \& M. Mzingelwa 2012. Death Rates in Public Hospitals of Eastern Cape Province of South Africa. Iranian Journal of Public Health 41,12: 19 25.

Csordas, T.J. \& A. Kleinman 1990. 'The Therapeutic Process'. In Fishel, C. Seargent \& T.M. Johnson 9eds.): Medical Anthropology: Contemporary Theory and Method. New York, NY: Praeger Publishers.

Denis, P. 2013. HIV/AIDS and Religion in sub-Saharan Africa: An Emerging Field of Enquiry. Archives de Sciences Sociales des Religions 164: 43 58. https://doi.org/10.4000/assr.25399

Fourcade, M., 2010. The Problem of Embodiment in the Sociology of Knowledge: Afterword to the Special Issue on Knowledge in Practice. Special Issue on Knowledge in Practice 14 September.

https://doi.org/10.1007/s11133-010-9173-x

Gilbert, L., T. Selikow, L. Walker 1996. Society, Health and Disease: An Introductory Reader for Health Professionals. Braamfontein, South Africa: Ravan Press.

Gross, C.L. 2015. Spirituality and Religion as a Social Determinant and Social Mediator of Health. Nashville, Tennessee: s.n.

Holman, S.R. 2015. Religion and the Social Determinants of Health. https://blog.oup.com (Accessed on 26 August 2018.)

Idler, E.L. 2014. Religion as a Social Determinant of Public Health. World 
Medical and Health Policy 7,2: 157 - 158.

https://doi.org/10.1093/acprof:oso/9780199362202.001.0001

Idler, E., J. Blevins, M. Kiser \& C. Hogue 2017. Religion, A Social Determinant of Mortality? A 10-year Follow-up of the Health and Retirement Study. PLOS ONE 20 December,12,12: 1 - 15.

https://doi.org/10.1371/journal.pone.0189134

PMid:29261682 PMCid:PMC5738040

Kaunda, CJ. \& I.A. Phiri 2016. Healing and Health in African Christianity. In

Phiri, I.A. et al. (eds.): Anthology of African Christianity. Oxford: Regnum Publishers.

Kolcaba, K. 2003. Comfort Theory and Practice: A Vision for Holistic Health

Care and Research. New York: Spring Publishing Company.

Lehohla, P. 2006. Migration and Urbanisation in South Africa. Pretoria: Statistics South Africa.

Leming, M.R. 1980. Religion and Death: A Test of Homans' Thesis. OMEGA

- Journal of Death and Dying 10,4: 347 - 364.

https://doi.org/10.2190/PPDF-DT3R-4J9N-QUV2

Mason, S. 2017. Introduction: HIV Testing, Disclosure, and Human Rights.

Journal of HIV/ AIDS and Social Services 16,3: wi - wiv.

https://doi.org/10.1080/15381501.2017.1370066

Meier, B.P., S. Schnall, N. Schwarz \& J.A. Bargh, 2012. Embodiment in Social

Psychology. 2 Cognitive Science Society 1,12: 1756 - 8765.

Montgomery, B.D., L. Keegan \& C.E. Guzzetta 2005. Pocket Guide for

Holistic Nursing. Sudbury: Jones and Bartlett Publishers.

Patterson, E.F. 1998. The Philosophy and Physics of Holistic Health Care:

Spiritual Healing as a Aorkable Interpretation. Journal of Advanced

Nursing 22,02: 287 - 293.

https://doi.org/10.1046/j.1365-2648.1998.00533.x PMid:9515638

Pretorious, A., Z. Matebesi \& L. Ackermann 2013. Sociology for Healthcare Professionals. Cape Town: Juta and Company Ltd.

Schoeman, W.J. 2017. South African Religious Demography: The 2013 General Household Survey. HTS Teologiese Studies/Theological Studies 73,2: 3837. https://doi.org/10.4102/hts.v73i2.3837

Shabalala, Z. \& T. Dlamini 2018. HIV and AIDS in Swaziland and the Role of the Church. Germany: Ecumenical Service on Southern Africa.

Sharpley, N. 213. Churches and Service Delivery in South Africa: The Black Charismatic Church Ministries (BCCMs), as Agents for Service Delivery 
in the Eastern Cape. Durban : UKZN.

Short, W.E. \& B. Vissandjée 2017. Women Living with HIV in India: Looking Up from a Place of Stigma: Identifying Nexus Sites for Shange. Diversity and Equality in Health and Care 14,3: 159.

https://doi.org/10.21767/2049-5471.1000107

Sirri, I., G.A. Fava \& N. Sonino 2012. The Unifying Concept of Illness Behavior. Psychother Psychosom 82: 74 - 81.

https://doi.org/10.1159/000343508 PMid:23295460

Taylor, S., \& D. Field 1993. Sociology of Health and Health Care. London: Blackwell Scientific Publications.

WHO 2007. Faith-based Organizations Play a Major Role in HIV/AIDS Care and Treatment in Sub-Saharan Africa. Geneva: WHO .

WHO 2008. Closing the Gap in a Generation: Health Equity through Action on the Social Determinants of Health. Geneva: WHO.

World Council of Churches 1990. Healing and Wholeness: The Churches' Role in Health. German Institute for Medical Mission i-iv: 1 - 40. http://difaem.de/fileadmin/Dokumente/Publikationen/Dokumente_AErzt liche_Mission/healing (Accessed 15 Dececember 2018).

Wyngaard, A.V. 2013. Addressing the Spiritual Needs of People Infected with and Affected by HIV and AIDS in Swaziland. Pretoria: Faculty of Theology, University of Pretoria, and CEO of Shiselweni.

Nelly Sharpley

Director of Special Projects Walter Sisulu University (WSU) nsharpley@wsu.ac.za

Chammah J. Kaunda (PhD) Assistant Professor United Graduate School of Theology Yonsei University Korean Republic, and Research fellow for the Southern African Institute for Policy and Research (SAIPAR) pastorchammah@gmail.com 